\title{
La historia intelectual en México y sus conexiones
}

\section{Intellectual History in Mexico and its Connections}

\author{
Verónica Zárate Toscano \\ Instituto Mora \\ Plaza Valentín Gómez Farías \# 12 Col. San Juan Mixcoac \\ México D.F. C.P 03730, México \\ vztcmch@yahoo.com.mx
}

ReSumen Se presenta el itinerario seguido por la historia intelectual en México como herramienta teórica para el análisis de la realidad mexicana y también latinoamericana. Tomando como base las propuestas teóricas europeas y norteamericanas, se destaca la aplicación del llamado giro lingüístico que la ha dotado de características particulares. Asimismo, se mencionan algunas propuestas de otras escuelas de pensamiento que comparten ciertos rasgos de la historia intelectual y que bien podrían considerarse parte de esta escuela historiográfica. Se destaca el desarrollo de propuestas en varias instituciones mexicanas a través de seminarios, publicaciones y otros medios.

Palabras Clave giro lingüístico, historiografía, ideas, intelectuales

Abstract This paper develops the itinerary followed by intellectual history in Mexico used as a theoretic tool to analyze Mexican and Latin-American realities. Departing from the proposals made in Europe and North America, Mexican scholars followed the linguistic turn variation, which has introduced certain peculiarities. We take

\footnotetext{
Recebido: 6 de janeiro de 2015 | Aprovado: 2 de abril de 2015

http://dx.doi.org/10.1590/0104-87752015000200005

Varia Historia, Belo Horizonte, vol. 31, n. 56, p. 401-422, mai/ago 2015
} 
in count proposals from other schools of thought that share some characteristics of intellectual history and that could well be considered as an important part of this historiographic school. We emphasize the development of proposals in different Mexican institutions through seminars, publications and other sources.

KEYWORDS linguistic turn, historiography, ideas, intellectuals

\section{INTRODUCCIÓN}

El estudio de la historia intelectual nos lleva, en primer lugar, a tratar de definirla, cuestión que resulta bastante compleja, entre otras razones, porque esta corriente ha ido evolucionando y adaptándose a épocas y lugares y requeriría de un tiempo y un espacio del que no disponemos. En vez de referirnos a sus orígenes europeos y anglosajones, ${ }^{1}$ a sus revistas especializadas, ${ }^{2}$ etc., nos limitaremos a tratar de entender qué aspectos relevantes se han abordado en México para el análisis de este país y del resto de América Latina en términos generales.

Lo más notable es reconocer cómo el "giro lingüístico", propuesto por Quentin Skinner (1969, p.3-53; Palti, 1998), ha obligado a reflexionar más allá de los conceptos y lenguajes políticos a los que se limitaba buena parte de la historia política, a poner en duda los viejos paradigmas de la historiografía de las ideas (Polgovsky Ezcurra, 2010), y a dar prioridad al modo característico de producirlas (Palti, 2007). Enriquecida con estas herramientas, la historia intelectual con frecuencia trastoca los "límites" con otras corrientes historiográficas sin perder sus vínculos con ellas, lo que la dinamiza y flexibiliza las dimensiones a investigar. Lo que nos

1 Solo por mencionar a algunos de sus exponentes, debemos citar a John Dunn y Quentin Skinner en Gran Bretaña, Anthony Grafton y J. G. A. Pocock en Estados Unidos, Reinhart Koselleck en Alemania, Roger Chartier, François Dosse y Jean-François Sirinelli en Francia.

2 Intellectual History Review, revista de la International Society for Intellectual History http:// www.tandfonline.com/action/journalInformation?journalCode=rihr20\#.VDXsExb0VnF y Modern Intellectual History, publicada en Cambridge http://journals.cambridge.org/action/ displayJournal?jid=MIH. 
interesa destacar en estas líneas es la manera en que se ha aplicado la historia intelectual" para estudiar, analizar y comprender el devenir de México y cómo se conecta con otras tradiciones teórico-metodológicas.

Los resultados de las investigaciones realizadas a partir de esta propuesta pueden tener puntos en común o, por el contrario, hondas diferencias que hacen que puedan parecer opuestos, pero resultan complementarios para explicar un panorama general del pensamiento, cultura, ideas e intelecto. Sin embargo, existen estudiosos que se muestran escépticos en cuanto a la confusión entre la historia intelectual y la historia de las ideas y consideran que, en "su lugar, y con afanes cada vez más hegemonizantes, se ha desarrollado una historia cultural preferentemente vertida hacia las prácticas, los lugares y los vectores de la cultura de masas, así como la historia de los intelectuales" (Lempériere, 2007, p.198; Lempériere, 1992).

Otros autores consideran sin fundamento la crítica a la historia de las ideas en el sentido de que resulta obsoleta frente a las nuevas corrientes, y que no ha hecho grandes aportaciones recientemente, puesto que puede demostrarse que el estudio de los autores individuales no ha cedido su lugar a la teoría para explicar el siglo XIX, y se han realizado esfuerzos redituables en ese campo. ${ }^{3}$

Los colegas dedicados a estas investigaciones reconocen la dificultad que representa saber cuándo están haciendo historia intelectual, ya que no hay consenso en torno a cómo debe definirse. Stefan Collini consideró hace unos años que se había incrementado la auto-confianza entre quienes se describen como "historiadores intelectuales" y las auto-justificaciones eran cada vez menos necesarias porque se habían emancipado de la historia del pensamiento político (Collini, 2007, p.165-169). No puede pasarse por alto que en este campo historiográfico confluyen distintas disciplinas o modalidades, como la historia de la filosofía, de las ideas, de la ciencia, de las mentalidades, de la cultura, la lingüística, la crítica literaria, la sociología, la antropología cultural, la estética, la ética, etc (Illades; Suárez, 2012, p.11). Además de aquellos estudios que directa

3 AGUILAR RIVERA, 2008, p.179-187. Esta es una reseña muy crítica al libro de PALTI, 2007. 
y abiertamente se supone que forman parte de la historia intelectual, considero que existen otras investigaciones que bien podrían insertarse en esta manera de explicar el pasado, y a ellas me referiré más adelante.

\section{LA HISTORIA INTELECTUAL EN MÉXICO Y LATINOAMÉRICA}

La tradición historiográfica mexicana remonta los orígenes de la historia intelectual a la época en que José Gaos, exiliado español, llegó a México a desarrollar su análisis de historia de las ideas, al que se sumaron, con sus enfoques muy particulares, Leopoldo Zea, Luis Villoro, Juan Ortega y Medina y sobre todo Edmundo O 'Gorman (Granados; Matute; Urrego, 2010, p.19-20). Con sus colegas, discípulos y nuevos interesados, la tradición ha continuado y evolucionado adoptando el nombre de historia intelectual. La Facultad de Filosofía y Letras de la UNAM, El Colegio de México, ${ }^{4}$ y la Universidad Autónoma Metropolitana Unidad Cuajimalpa, ${ }^{5}$ entre otras instituciones, han respaldado esta tendencia y en ellas se realizan investigaciones ligadas a la historia intelectual, cuyos avances se enseñan en cursos universitarios y de posgrado, se discuten en seminarios de especialistas, se presentan en congresos y finalmente se plasman en publicaciones. ${ }^{6}$ Aunque el enfoque, en términos generales, se ha dirigido más hacia Latinoamérica, también se han hecho importantes contribuciones referentes al caso exclusivo de México.

Las fases por las que ha pasado la historia intelectual están en función de lo que cada circunstancia, época o momento selecciona como su objeto de estudio. Se han realizado contribuciones importantes tomando como núcleo principal a los intelectuales, pero los matices introducidos han hecho que se analicen en su función frente al estado, ${ }^{7}$ como redes

4 El Seminario de historia intelectual de El Colegio de México funciona desde 2000, dirigido por Carlos Marichal, Horacio Crespo y Guillermo Palacios. http://shial.colmex.mx/

5 http://dcsh.cua.uam.mx/cuerpos-academicos/historia-actores-espacios-e-ideas/

6 No puede pasarse por alto la contribución de MARICHAL, 1978. Libro surgido de un ciclo de conferencias. La tradición ha sido continuada por su hijo Carlos Marichal dirigiendo un seminario sobre el tema en El Colegio de México.

7 Mencionamos solamente los que se ocupan del caso mexicano: CAMP, 1985 y KRAUZE, 1976. 
intelectuales (Melgar Bao, 2003), en su relación con las revistas, los lenguajes y discursos, como parte de la república de las letras (Illades, 2005), en sus relaciones continentales, su vinculación con la historia de la lectura, la cultura científica, la literatura (Schmidt-Welle, 2014), las sociedades, la recepción de ideas europeas en América, y no podrían pasarse por alto la reflexión teórica metodológica en México (Trejo; Matute, 2005; Zermeño, 2002), A partir de estas ideas, Aimer Granados, Álvaro Matute y Miguel Ángel Urrego coordinaron un libro que presenta las tendencias y temas latinoamericanos de historia intelectual que "simplemente tiene como ambición el hacer que se expresen al mismo tiempo las obras, sus autores y el contexto que las ha visto nacer" (Granados; Matute; Urrego, 2010, p.7).

Pero hablando en términos más generales, las publicaciones que se inscriben en esta corriente incluyen estudios que van desde la producción de ideas y su circulación hasta su consumo. Podría decirse también que es una historia comparativa de la cultura que produce ideas y la cultura que las consume. Peter Burke (2007, p.159-164) considera necesario ocuparse de los diversos medios de los que se valen las ideas para su transmisión: orales, pictóricos y escritos, como veremos más adelante.

Aunque no podríamos referirnos a toda la producción mexicana que se considera "historia intelectual", mencionaremos algunos ejemplos de aquellos estudios relacionados con el análisis de los autores, su expresión textual, el entorno o contexto donde se realizan y la forma en que se socializan. Uno de los medios para realizar este tipo de análisis es a través de las revistas. ${ }^{8}$ Aimer Granados ha coordinado un libro que da entrada a esta perspectiva de la historia intelectual, tomando a las revistas como soportes materiales de las ideas que generan lazos culturales de acercamiento e incluso ruptura entre los intelectuales. Además de analizar la difusión de "ideas-texto", las revistas son el germen de

8 No podemos dejar de mencionar aquí, aunque lo abordemos en otras líneas de este texto, el sitio fundamental que ocupa la principal revista latinoamericana consagrada a la historia intelectual, Prismas, publicada desde 1997 por el Centro de Historia Intelectual, Departamento de Ciencias Sociales de la Universidad Nacional de Quilmes, Argentina, http://www.scielo. org.ar/scielo.php?script=sci_serial\&lng=es\&pid=1852-0499\&nrm=iso. 
comunidades académicas, redes de empresarios culturales, editores y autores (Granados, 2012, p.9-10). Aunque en México no hay revistas especializadas de historia intelectual (Garciadiego, 2001, p.221-231), las más vanguardistas y también algunas de las más antiguas van dando cabida a los artículos que abordan esta temática. Sólo por citar un ejemplo, podríamos mencionar Historia y Grafía, publicada por la Universidad Iberoamericana. ${ }^{9}$

Las revistas no son el único tipo de publicaciones que han merecido la atención en su papel de medio de circulación de las ideas. En una obra en tres volúmenes, titulada La república de las letras, ${ }^{10}$ un nutrido grupo de investigadores, coordinado por Belem Clark y Elisa Speckman, ha analizado revistas, periódicos, folletos y autores destacados del siglo XIX en México (Clark de Lara; Speckman Guerra, 2005). Y precisamente el primer siglo de vida independiente ha sido escudriñado en cuanto a la creación y consolidación de las empresas culturales de impresores, lectores, libreros, etc. por un grupo coordinado por Laura Suárez de la Torre (Suárez de la Torre; Castro, 2001; Suárez de la Torre, 2003). Cabe señalar que una vertiente a la que ellos también han dedicado sus esfuerzos es la transferencia cultural de las ideas, particularmente entre México y Francia (Andries; Suárez de la Torre, 2009). Otro grupo encabezado por Miruna Achim y Aimer Granados se ha interesado por analizar cómo "personas, cosas, libros, textos, estilos se desplazan y circulan, son intercambiados, se cruzan, van y vienen". Estos itinerarios variados y complejos son estudiados como actos "dinámicos, producto de usos, fuerzas, encuentros y diálogos concretos, y a su vez capaces de actuar sobre sus entornos temporales y espaciales inmediatos" (Achim; Granados, 2011, p.11).

9 Historia y Grafía, n. 23, 2004, está prácticamente dedicada a la historia intelectual. http:// dialnet.unirioja.es/servlet/ejemplar?codigo $=333320$ Particularmente interesante es el texto que reproducen de DOSSE, 2004, ya que sirve como base para varios de sus artículos.

$10 \mathrm{La}$ "república de las letras" es una propuesta de interpretación que ha sido utilizada ampliamente. Lo más significativo tal vez sea el libro de RAMA, 1998, y recientemente por FUMAROLI, 2013. 
Los estudios de la historia del libro están indisolublemente relacionados con todo lo anterior y en México existe una gran tradición en este campo que no siempre ha sido considerada parte de la historia intelectual (Torre Villar, 1999; Garone Gravier; Álvarez, 2012). Recientemente Carlos Ilades y Rodolfo Suárez coordinaron un libro que analiza cómo se ha percibido México como problema a partir de la historia intelectual. Su objetivo, como explican en la introducción, es "situar un conjunto de textos en el ámbito de su recepción y, a partir de allí, ponderar su impacto dentro del campo intelectual, y sobre todo, en la discusión pública mexicana”. Presentan los estudios hechos por un conjunto de autores contemporáneos que analizan cómo, a lo largo de 150 años, se ha reflexionado sobre los problemas que enfrenta el país y cuáles han sido las soluciones propuestas para resolverlos. Una primera parte, dedicada al "diagnóstico de la nación", aborda a Mariano Otero, Nicolás Pizarro, Francisco Pimentel, Victor Considerant, Andrés Molina Enríquez, Daniel Cosío Villegas, José Revueltas, Enrique Krauze y Carlos Pereyra. La segunda se ocupa de los "instrumentos de análisis" aportados por Julio Guerrero, Samuel Ramos, Octavio Paz, Luis Villoro, Alfonso Reyes, Santiago Ramírez, Rodolfo Stavenhagen, Larisa Adler y Guillermo Bonfil Batalla en sus obras principales. Y como dicen los compiladores, "la historia de estos libros y de su lectura es una forma más de introducirse y hasta aprehender la historia de las épocas en que fueron escritos, leídos e incluso de aquellas en las que habrán perdido notoriedad" (Illades; Suárez, 2012, p.12).

Cabe agregar que otros medios utilizados para la transmisión de las ideas, son los pictóricos. Esto nos lleva al campo de la historia del arte, y concretamente a la cultura visual que, a últimas fechas, ha enriquecido el análisis histórico y apoyado estudios de tipo político, social. Las imágenes, desde las capturadas con las técnicas más antiguas hasta las producidas por la modernidad, fijas o en movimiento, han permitido aproximaciones novedosas no sólo por sus contribuciones al conocimiento del arte sino en relación con la sociedad, la política, la economía, y por supuesto, la cultura, las ideas. Se ha llegado a considerar que los creadores de tales obras forman parte de la elite intelectual, aunque 
algunos estudios están enfocados más a las manifestaciones populares. Pero sobre todo contribuyen a la creación del imaginario o las representaciones, materia de la que se ocupa la historia de las mentalidades. Así, las imágenes portadoras de historia y de tiempo y su facilidad de comprensión, han permitido a Serge Gruzinski analizar el México colonial y barroco a través de las imágenes como medio de transmisión de ideas y la forma en que fueron percibidas, recibidas o rechazadas. ${ }^{11}$ La dimensión iconográfica se utiliza para la fijación de la historia y se construye una versión única u oficial de la historia, pero para hacerla accesible a la población, se buscan la manera de representarla plásticamente. Se pueden comunicar los hechos a través de monumentos, esculturas, pinturas, grabados, billetes, timbres, música, periódicos murales, cuadros vivientes, libros de texto y ceremonias cívicas conmemorativas, con ello se revaloran los rumores, chismes y sobre todo los mitos.

Burke también se refiere a los medios orales como transmisores de ideas. En México existe un importante grupo de especialistas en historia oral que ha recogido testimonios de actores y testigos de la historia reciente relacionados con movimientos sociales, la diplomacia, el cine, la arquitectura, etc., pero también de voces no tan públicas que también contribuyen a la transmisión de saberes y de ideas. ${ }^{12}$

A estos medios orales, se suman los testimonios sonoros, y aunque en la revisión que hemos hecho encontramos pocas referencias a la música, ${ }^{13}$ no podemos pasar por alto el rol que desempeñan en la transmisión de la cultura, en la reafirmación de la identidad y en la conformación de la memoria histórica. Por ello hay que resaltar la imperiosa necesidad de

11 GRUZINSKI, 1990. Traducción GRUZINSKI, 2006.

12 El Archivo de la Palabra registra las voces del pasado y del presente de personalidades destacadas, políticos, científicos, artistas y literatos, así como de aquellos que en algún momento estuvieron ligados a la revolución, de los vecinos que han visto crecer la ciudad, etc. Las grabaciones y transcripciones se localizan en el Instituto de Investigaciones Dr. José María Luis Mora, en la Biblioteca Nacional de Antropología del INAH, en la Dirección de Estudios Históricos del INAH y en la Biblioteca Nacional de España.

13 Habrá que prestar atención a lo que hacen la Fonoteca del INAH y demás instituciones relacionadas con los acervos musicales. 
aprovechar la música para el conocimiento del pasado. Las partituras en su aspecto musical y visual, los compositores y sus obras, los intérpretes, el público, la enseñanza, los militares, los instrumentos proporcionan información muy valiosa y poco atendida. Actualmente y como parte de mi proyecto personal relacionado con los lugares de la memoria, he prestado atención a la música en la que se puede encontrar no solo un reflejo sino un actor que interviene en las transformaciones sociales y culturales de una región, así como en la formación de naciones e identidades (Zárate Toscano, 2010, p.34-43, p.74-75; Zárate Toscano, 2014, p.230-289).

Es pertinente registrar que otra vertiente importante de la historia intelectual es el estudio de los intelectuales propiamente dichos, analizados en términos individuales, como producto de su momento, y como parte de lo que podríamos reconocer como verdaderas comunidades científicas. Leticia Mayer analizó los significados culturales con que la elite intelectual de la primera mitad del siglo XIX mexicano dotó al conocimiento estadístico, reconociendo su carácter utilitario. En este libro es indisoluble la relación entre la historia de la ciencia y la historia cultural (Mayer Celis, 1999).

A los intelectuales también se les ha visto como parte de una generación, a partir de la propuesta de Robert Whol (1979). Un ejemplo serían los estudios de Charles Hale con su enfoque hacia el liberalismo decimonónico, ${ }^{14}$ sobre los que reconoce que "puesto que los intelectuales estaban a menudo cerca del gobierno, caracterizo a veces mis estudios mexicanos como buscando 'las bases intelectuales de los supuestos políticos"' (Hale, 2007, p.195-196). Por su parte, Enrique Krauze con sus caudillos culturales (Krauze, 1976), libro que es a la vez de historia intelectual y biografía colectiva, hace pensar que la historia intelectual es una historia de las ideas de carne y hueso (Matute, 1977, p.222-224). Ambos destacan el papel protagónico de los intelectuales en el desarrollo político, financiero y cultural de México. Pero François-Xavier Guerra fue más allá cuando, a través de la prosopografía, identificó

14 Principalmente véase HALE, 1991. 
las redes de contacto entre los integrantes de este grupo en el paso del antiguo régimen a la revolución (Guerra, 1988).

Carlos Marichal y Alexandra Pita han coordinado un libro que ha puesto énfasis en el imperialismo como hilo conductor del pensamiento latinoamericano en el primer tercio del siglo XX. Para ello parten del análisis de cómo se ha percibido la intromisión de potencias extranjeras como freno para el desarrollo de América Latina, manifestada en una decena de textos con los que se pretende demostrar que las "corrientes de pensamiento y expresión antimperialistas han carecido de homogeneidad ideológica, conceptual e instrumental" (Pita González; Marichal Salinas, 2012, p.9). El hecho de limitarse a las obras generadas en un periodo histórico acotado bien se podría relacionar con lo que Luis González llama "la ronda de las generaciones" (González y González, 1997).

Uno de los temas que se ha sido abordado desde esta "compleja pero rica plataforma que ofrece la historia intelectual y cultural de América Latina" es el de las identidades nacionales. Carlos Marichal y Aimer Granados, en la introducción del libro colectivo, ven a la historia intelectual "como lente de la metamorfosis" para ofrecer una discusión multifacética del tema (Granados; Marichal, 2004). Reunieron una colección de ensayos con el objetivo de destacar la importancia de recuperar la riqueza y diversidad de las múltiples contribuciones realizadas en el siglo XIX y principios del XX por destacados intelectuales y políticos en el proceso de búsqueda y construcción del concepto siempre cambiante de una América Latina unida. Con ellos se hace evidente que la identidad se construye a partir de reconocer y afirmar lo auténticamente propio y contrastar y singularizarse frente a las demás culturas. Uno de los recursos para lograrlo es la conformación de la memoria histórica.

En ese sentido y para comprender al pasado en Latinoamérica, habría que mencionar el libro coordinado por François Xavier Guerra, Mémoires en devenir. Amérique Latine XVIe-XXe siècle (1994), en el que se analiza, en la larga duración, las batallas libradas en torno a la memoria y el olvido con respecto al pasado del continente americano, tanto durante la época colonial, como en los siglos XIX y XX. Así, los autores 
de los distintos ensayos transitaron por esta problemática desde México hasta Argentina, pasando por Guatemala, Perú, Colombia, Venezuela, Brasil y Chile. En la introducción (p.9-27), Guerra escribió que "Si la memoria se atiene solo a los recuerdos orales, se extingue. Para pasar esos límites, tiene que apuntalarse en otros medios que le permitan perpetuarse, sobre apoyos diversos -escritos, imágenes, monumentos, ceremonias, rituales- y sobre hombres o instituciones encargados de preservarlos, crearlos o recrearlos, interpretarlos o reinterpretarlos". Es así como se entra en el dominio de las construcciones "memoriales" a las que pertenece la historia.

También hemos encontrado un interés por la búsqueda de la identidad a través del análisis de los nombres de los países en América Latina (Chiaramonte; Marichal; Granados, 2008). En esencia, lo que se pretende es entender cómo la selección de dichas denominaciones está relación directa con la conformación del estado y la construcción de identidades nacionales. En ese sentido, los nombres de los países miran al presente pero sobre todo al futuro de una nación en vías de consolidación.

Podríamos pensar, en oposición a esta idea, en los momentos en que se decide hacer una sistematización de la nomenclatura de poblaciones, y particularmente de las calles. De esta forma, se voltea al pasado para seleccionar aquellos nombres de personajes, fechas, hechos que proporcionen elementos para reafirmar la memoria histórica. La nomenclatura es una representación, un discurso alejado de lo real, algo subjetivo que pueda significar, de forma simbólica, un status y un rango, como diría Roger Chartier (1992, p.56-57). Porque la nomenclatura como discurso político va a ser susceptible de cambiar según los intereses de los dirigentes, de los protagonistas de un determinado periodo histórico. Además, tiene que aparecer como un discurso que represente a todos, pero finalmente los nuevos símbolos de identidad que se imponen están acordes con los intereses del grupo en el poder, que busca crear un consenso a su alrededor. Por eso se resucitan ciertos valores significativos que se hacen válidos para ese momento y se borran todos aquellos referentes que resulten incómodos para el discurso dominante. 
Como parte del gran proyecto de Pierre Nora de los lieux de mémoire, Daniel Milo se encargó de analizar los nombres de calles francesas (Milo, 1997, p.1887-1918), y con este ejemplo, se hicieron ejercicios similares en otros lugares, particularmente en Lima (Ramón, 1997, p.85-99), y en México, donde se demostró la importancia de la selección de los nombres de las calles en la conformación del discurso de la memoria histórica y en la formación de ese nacionalismo que se buscaba inculcar entre los mexicanos (Zárate Toscano, 2007, p.329-384).

El principal exponente de la teoría sobre los lugares de la memoria es el francés Pierre Nora quien, entre 1984 y 1992, coordinó la obra Lieux de Mémoire ${ }^{15}$ con la colaboración de colegas de diversas disciplinas, como historia, literatura, ciencias política, sociología, interesados todos por reconocer los "lugares de la memoria" de la identidad nacional francesa y la manera en que se habían construido. Su idea original fue estudiar el sentimiento nacional, no a la tradicional manera temática o cronológica sino analizando los lugares en los que la herencia colectiva de Francia había cristalizado y los lugares principales en que se enraizaba la memoria colectiva con el fin de crear una vasta topología del simbolismo francés. El trabajo explicó cómo la memoria unificaba a las comunidades, creaba identidades sociales y dramatizaba el hecho de que la conciencia del pasado propio era sintomática de la desaparición de ciertas tradiciones vivientes.

Según Peter Burke, el "giro cultural", ha afectado a la historia intelectual en la reevaluación de la idea de la tradición (Burke, 2007, p.161), a la que se le atribuye un papel preponderante en la transmisión de las ideas. Hace ya algunas décadas, Eric Hobsbawm y Terence Ranger hicieron una propuesta primordial al analizar lo que llamaron la invención de la tradición. ${ }^{16}$ Este término incluye tanto las "tradiciones" realmente inventadas, construidas y formalmente instituidas, como aquellas que emergen en un periodo breve y mesurable, y se establecen con gran

15 NORA, 1997, 3 vols., (Quarto). La primera edición es de 1984-1992. Asimismo se tradujo al inglés con el título NORA, 1996.

16 HOBSBAWM, RANGER, 1983. Traducción castellana HOBSBAWM, RANGER, 2002. 
rapidez. La tradición inventada implica un grupo de prácticas, normalmente gobernadas por reglas aceptadas abierta o tácitamente y de naturaleza simbólica o ritual, que buscan inculcar determinados valores o normas de comportamiento por medio de su repetición, lo cual implica automáticamente una continuidad con el pasado. El elemento de la invención es claro desde el momento en que la historia, que se convirtió en parte del fundamento del conocimiento y la ideología de una nación, no es lo que realmente se ha conservado en la memoria popular, sino lo que se ha seleccionado, escrito, dibujado, popularizado o institucionalizado por aquellos cuya función era hacer precisamente esto, es decir, los intelectuales al servicio del estado. Y según Burke, entonces, podría hablarse de una tradición intelectual.

Dentro de las tradiciones, podríamos incluir desde el folklor, la comida y todos los que son resultado de las ideas de los seres humanos, insertos en lo que se conoce como patrimonio intangible. Pero estos conocimientos, para sobrevivir, deben afianzarse en la memoria individual o colectiva, requieren aprovechar mecanismos que les aseguren una presencia, que les permitan materializarse, de ahí la importancia de los lugares de la memoria. El aspecto intelectual de la memoria pasa de algo inmaterial como las ideas y pensamientos a su materialización en objetos. Con la historia de la cultura material, podemos ligar la utilización, fabricación y circulación de esos objetos pero sobre todo la manera en que fueron concebidos, planteados, ideados. Y también la forma en que los seres humanos se aproximan a ellos y los aceptan o rechazan. Estas actitudes nos llevan hacia la historia de las mentalidades y sus aproximaciones hacia la religión, los sentimientos, las representaciones. Dentro de éstas podríamos incluir las ideas en torno a la nación ya mencionadas.

La historia intelectual también tiene conexión con la historia de las mentalidades, aunque, como ha escrito Solange Alberro, ésta actúa en campos de interés dominados por la sensibilidad, en oposición a los que son regidos por la conciencia. En ese sentido se contrapone a la historia de las ideas que estudia los procesos que corresponden a la obra o a la cultura de un autor específico (Alberro, 1992, p.333-351). Sin embargo, algunos de los principales exponentes de esta escuela han transitado 
hacia un tipo de análisis que parte de ideas individuales que generan procesos culturales colectivos, y de esta manera se podrían inscribir más en la historia cultural, cercana a su vez a la intelectual en el sentido de que el imaginario y las representaciones emanan del intelecto, de las ideas. El hecho de que sean individuales o colectivas puede distinguir la aproximación que de ellas hace una corriente o la otra, pero en el fondo, tienen más puntos en común de lo que podría pensarse. La larga duración, sobre la que se sustenta el análisis de las actitudes y los lentos cambios en las mentalidades se podría contraponer a la especificidad del pensamiento de un determinado individuo en un momento específico, pero su propuesta intelectual, las ideas que genera, pueden constituirse en una ideología que llega a influir y trascender por varias generaciones, alcanzar a las masas anónimas y regir sus comportamientos, generar representaciones y simbolismos que son una materialidad visible de las ideas.

Robert Darnton, por ejemplo, considera que la historia intelectual se puede dividir en cuatro modalidades principales: una historia de las ideas, una historia intelectual propiamente dicha, una historia social de las ideas y una historia cultural. La primera estudiaría los tratados filosóficos, una especia de historia de la filosofía; la segunda se ocuparía de las opiniones y movimientos artísticos; la tercera de las ideologías y difusión de ideas y la cuarta sería el estudio de las visiones del mundo, más precisamente de las mentalidades. Éstas las entiende como el examen del punto de vista y percepción del hombre común en cuanto a los hechos y no tanto al análisis de los propios hechos en sí. ${ }^{17}$

Las metodologías de historia global y trasnacional dan una nueva perspectiva a la historia intelectual al traspasar las tradicionales fronteras y de ahí la importancia de la circulación de las ideas y las historias conectadas que permiten, por ejemplo, que Serge Gruzinski pueda destacar cómo, de manera casi simultánea, se llevan a cabo procesos similares en México y en China, ${ }^{18}$ en Brasil y en África, y que los escritos

17 DARNTON, 1990b, traducido como DARNTON, 1990a, p.228. Traducción española DARNTON, 2010. Recientemente ha publicado, DARNTON, 2014.

18 GRUZINSKI, 2011a. Traducción al inglés: GRUZINSKI, 2014 b. 
de los intelectuales europeos circulen, sean recibidos y conectados entre sí en las cuatro partes del mundo. ${ }^{19}$ Cabe destacar que casi todos los estudios de historia intelectual tienen como eje cronológico los siglos XIX y XX porque están ligados al estado nación, pero esta propuesta bien podría aplicarse al período colonial, como lo ha hecho Gruzinski.

\section{AlCANCES Y REFLEXIONES}

Para que una propuesta metodológica llegue a consolidarse, debe trascender barreras temporales, espaciales e incluso teóricas y debe contribuir a la explicación de la realidad adecuándose a las necesidades de cada tiempo y lugar. En este sentido, el itinerario de la historia intelectual nos muestra cómo se ha desarrollado en distintos puntos del planeta con diferentes intensidades. Sus alcances han sido también de variada índole, y cada vez se han buscado nuevos mecanismos para difundirla, más allá de los libros y las revistas que suelen dar a conocer los resultados de seminarios y congresos. Sin ir más lejos, en noviembre de 2014 se efectuó en Argentina el segundo Congreso de Historia Intelectual de América Latina, dedicado en esta ocasión a "La biografía colectiva en la historia intelectual latinoamericana" ${ }^{20}$ En la convocatoria se destacaba que la historia intelectual está inserta en un proceso de profunda renovación "no solo en lo que atañe a sus métodos sino incluso en relación a su propio objeto". El programa mostraba algunos atisbos de esta "renovación" pero en general las preocupaciones y temáticas que se incluían no distaban mucho de lo que se ha venido discutiendo en las últimas décadas.

Por otro lado, para darle un mayor estímulo a los jóvenes académicos interesados en esta escuela de pensamiento, el Grupo "Trabajo intelectual, pensamiento y modernidad en América Latina, siglos XIX y XX” de la Asociación Europea de Historiadores Latinoamericanistas (AHILA) y

19 GRUZINSKI, 2004. Traducción española GRUZINSKI, 2011b. Traducción portuguesa como: GRUZINSKI, 2014a.

20 http://www.cedinci.org/jornadas.htm 
el Cuerpo Académico "Historia y Cultura" del Instituto de Investigaciones Histórico Sociales de la Universidad Veracruzana, en México, instituyeron un premio para un artículo de este "dominio" escrito por un "investigador emergente". ${ }^{21}$ De esta manera se espera alentar a las nuevas generaciones a que dediquen sus esfuerzos a dar explicaciones históricas a la realidad mexicana a partir de esta propuesta metodológica. Además, se espera que los esfuerzos institucionales sean fructíferos en este campo que, como tantos otros, nos ha llegado a México desde otras latitudes y nos ha ayudado al análisis de nuestra realidad.

Lo que hemos apuntado en estas líneas es la manera en que se ha desarrollado en México este movimiento global. La categoría de historia intelectual es tan amplia que probablemente no hemos incluido a todos sus representantes ya que resulta complicado contener toda la multiplicidad de posibilidades. Además, importar las escuelas de pensamiento de otras regiones genera algunos problemas ya que, al introducir las modificaciones necesarias para adaptarlas a realidades distintas a las que existen en las regiones que las generaron, implica frecuentemente romper los moldes y las propuestas originales e incluso traicionar su conceptualización. Para el caso mexicano podríamos seguir a quienes confirman la existencia del intelectual de estado, o por el contrario, asumir la posibilidad de una generación contestataria, opositora, etc.

Lo importante de señalar es que, cuando una propuesta tiene un efecto en la cultura, se adopta, genera escuela, se lee y llega a tener una influencia en el pensamiento y en la sociedad. Y esto podría afirmarse respecto a la historia intelectual en México, aunque en su vertiente relacionada con el giro lingüístico no ha llegado a entrar plenamente en las universidades y centros de investigación ya que es demasiado teórica o crítica y se contrapone a la tradición positivista que sigue privando en muchos lugares. Sin embargo, esa frontera poco a poco se está diluyendo y se han hecho importantes contribuciones. Por ello sería pertinente analizar con más detalle sus alcances, pero esa es una tarea que queda pendiente para otra ocasión.

21 http://www.uv.mx/blogs/tipmal/tag/historia-intelectual/ 


\section{REFERENCIAS BIBLIOGRÁFICAS}

ACHIM, Miruna; GRANADOS, Aimer, (comps.). Itinerarios e intercambios en la historia intelectual de México. México: UAM, Unidad Cuajimalpa, CONACULTA, 2011.

AGUILAR RIVERA, José Antonio. El tiempo de la teoría: la fuga hacia los lenguajes políticos. A contra corriente. Una revista de historia social y literatura de América Latina, vol. 6, n. 1, p.179-187, 2008.

ALBERRO, Solange. La historia de las mentalidades: trayectoria y perspectivas. Historia mexicana, vol. XLII, n. 2 (166), p.333-351, oct.-dic. 1992. ANDRIES, Lise; SUÁREZ DE LA TORRE, Laura (coords.). Impressions du Mexique et de France: imprimés et transferts culturels au XIX siècle= Impresiones de México y de Francia: edición y transferencias culturales en el siglo XIX (Horizons américains) México: Editions de la Maison des Sciences de L'Homme, Instituto de Investigaciones Dr. José María Luis Mora, 2009.

BURKE, Peter. La historia intelectual en la era del giro cultural. Prismas, Revista de historia intelectual, n. 11, p.159-164, 2007.

CAMP, Roderic. Los intelectuales y el Estado en el México del siglo XX. México: FCE, 1985.

CHARTIER, Roger. El Mundo como representación. Historia cultural: entre práctica y representación. Barcelona: Editorial Gedisa, 1992.

CHIARAMONTE, José Carlos; MARICHAL, Carlos; GRANADOS, Aimer (comps.). Crear la nación: los nombres de los países de América Latina. Buenos Aires: Editorial Sudamericana, 2008.

CLARK DE LARA, Belem; SPECKMAN GUERRA, Elisa (eds.). La república de las letras: asomos a la cultura escrita del México decimonónico, 3 vols. (Ida y regreso al siglo XIX) México: UNAM, Coordinación de Humanidades, 2005.

COLLINI, Stefan. Escuchar a escondidas entre los arbustos. Historia intelectual y crítica literaria. Prismas, Revista de historia intelectual, n. 11, p.165-169, 2007.

DARNTON, Robert. El beso de Lamourette. Reflexiones sobre historia cultural. Buenos Aires: FCE, 2010. 
DARNTON, Robert. El diablo en el agua bendita o el arte de la calumnia de Luis XIV a Napoleón (Colección historia) México: FCE, 2014.

DARNTON, Robert. O beijo de Lamourette: Mídia, cultura e revolução. São Paulo: Companhia das Letras, 1990a.

DARNTON, Robert. The Kiss of Lamourette: Reflections in Cultural History. New York: Norton, 1990b.

DOSSE, François. La historia intelectual después del linguistic turn. Historia y grafía, n. 23, p.17-54, 2004.

FUMAROLI, Marc. La República de las Letras. Madrid: El Acantilado, 2013.

GARCIADIEGO, Javier. Revistas revisitadas: ventana a la historiografía mexicana del siglo XX. Historia Mexicana, vol. LI, n. 2, p.221-231, octu.dic. 2001.

GARONE GRAVIER, Marina; ÁLVAREZ, Marisa (eds.). Miradas a la cultura del libro en Puebla: bibliotecas, tipógrafos, grabadores, libreros y ediciones en la época colonial. Puebla: Gobierno del Estado de Puebla, Consejo Estatal para la Cultura y las Artes de Puebla, Educación y Cultura, Asesoría y Promoción, UNAM, 2012.

GONZÁLEZ Y GONZÁLEZ, Luis. La Ronda de Las Generaciones, vol. 6 (Obras completas de Luis González y González) México: Clío, 1997.

GRANADOS, Aimer (coord.). Las revistas en la historia intelectual de América Latina: redes, política, sociedad y cultura. México: Universidad Autónoma Metropolitana, Unidad Cuajimalpa, 2012.

GRANADOS, Aimer; MARICHAL, Carlos (comps.). Construcción de las identidades latinoamericanas: ensayos de historia intelectual siglos XIX y XX. México: El Colegio de México, Centro de Estudios Históricos, 2004. GRANADOS, Aimer; MATUTE, Álvaro; URREGO, Miguel Ángel (eds.). Temas y tendencias de la historia intelectual en América Latina. Morelia: Universidad Michoacana de San Nicolás de Hidalgo, Instituto de investigaciones Históricas, UNAM, Instituto de Investigaciones Históricas, 2010. GRUZINSKI, Serge. A guerra das imagens. De Cristóvão Colombo a Blade Runner (1492-2019). São Paulo: Companhia das Letras, 2006.

GRUZINSKI, Serge. As Quatro partes do Mundo. História de uma Mundialização. Belo Horizonte: Ed. UFMG, São Paulo: EDUSP, 2014a. 
GRUZINSKI, Serge. L’aigle et le dragon. Démesure et mondialisation au XVIe siècle. Paris: Fayard, 2011a.

GRUZINSKI, Serge. La guerre des images de Christophe Colomb à Blade Runner (1492-2019). Paris: Fayard, 1990.

GRUZINSKI, Serge. Las cuatro partes del mundo: Historia de una mundialización. México: Fondo De Cultura Económica, 2011b.

GRUZINSKI, Serge. Les Quatre parties du monde. Histoire d'une mondialisation. Paris: Editions de la Martinière, 2004.

GRUZINSKI, Serge. The eagle and the dragon. Globalization and European dreams of conquest in China and America in the Sixteenth century. Cambridge: Polity Press, 2014b.

GUERRA, François Xavier (ed.). Mémoires en devenir. Amérique Latine XVIe-XXe siècle. (Collection de la Maison des Pays Ibériques, 62, Association Française des Sciences Sociales Pour l'Amérique Latine) Paris, Bordeaux: Maison des Pays Ibériques, 1994.

GUERRA, François Xavier. México: del Antiguo Régimen a la Revolución, 2 vols. (Sección de obras de historia) México: Fondo de Cultura Económica, 1988.

HALE, Charles A. Declaración para Prismas. Prismas, Revista de historia intelectual, n. 11, p.195-196, 2007.

HALE, Charles A. La transformación del liberalismo en México a fines del siglo XIX. México: Vuelta, 1991.

HOBSBAWM, Eric; RANGER, Terence (eds.). La invención de la tradición. Barcelona: Crítica, 2002.

HOBSBAWM, Eric. The invention of tradition. Cambridge: Cambridge University Press, 1983.

ILLADES, Carlos. Nación, sociedad y utopía en el romanticismo mexicano. México: CONACULTA, 2005.

ILLADES, Carlos; SUÁREZ, Rodolfo (coords.). México como problema: esbozo de una historia intelectual. México: UAM, Unidad Iztapalapa y Unidad Cuajimalpa, Siglo Veintiuno Editores, 2012.

KRAUZE, Enrique. Los caudillos culturales en la revolución mexicana. México: Siglo XXI, 1976. 
LEMPÉRIERE, Annick. Intellectuels, Etat et société au Mexique : les clercs de la nation, 1910-1968. Paris: L'Harmattan, 1992.

LEMPÉRIERE, Annick. La historia político-intelectual, de Francia a América Latina. Prismas, Revista de historia intelectual, n. 11, p.197-201, 2007.

MAYER CELIS, Leticia. Entre el infierno de una realidad y el cielo de un imaginario: estadística y comunidad científica en el México de la primera mitad del siglo XIX. México: El Colegio de México, Centro de Estudios Históricos, 1999.

MARICHAL, Juan. Cuatro fases de la historia intelectual latinoamericana 1810-1970. Madrid: Fundación Juan March, Catedra, 1978.

MATUTE, Álvaro. Reseña sobre KRAUZE, Enrique, Caudillos culturales en la Revolución Mexicana, México, Siglo XXI, 1976, 332 p.. Estudios de Historia Moderna y Contemporánea de México, vol. 6, p.222-224, 1977.

MELGAR BAO, Ricardo. Redes e imaginarios en el exilio en México y América Latina 1934-1940. Buenos Aires: Libros en Red, 2003.

MILO, Daniel. Le nom des rues. In: NORA, Pierre (dir.). Les lieux de mémoire, vol. 2.. Paris: Gallimard, 1997. p.1887-1918.

NORA, Pierre (dir.). Les lieux de mémoire, 3 vols.. Paris: Gallimard, 1997.

NORA, Pierre (dir.). Realms of memory: rethinking the French past. New York: Columbia University Press, 1996.

PALTI, Elías José. El tiempo de la política. El siglo XIX reconsiderado. Buenos Aires: Siglo XXI Argentina, 2007.

PALTI, Elías José. "Giro lingüístico" e historia intelectual: Stanley Fish, Dominick Lacapra, Paul Rabinow y Richard Rorty. (Colección Intersecciones) Buenos Aires: Universidad Nacional de Quilmes, 1998.

PITA GONZÁLEZ, Alexandra; SALINAS, Carlos Marichal (coords.). Pensar el antiimperialismo: ensayos de historia intelectual latinoamericana, 19001930. México: El Colegio de México, Centro de Estudios Históricos, Universidad de Colima, 2012.

POLGOVSKY EZCURRA, Mara. La historia intelectual latinoamericana en la era del "giro lingüístico". Nuevo Mundo Mundos Nuevos [En ligne], Questions du temps présent, mis en ligne le 27 octobre 2010. Disponible en: http://nuevomundo.revues.org/60207; acceso en: 06 out. 2014. 
RAMA, Ángel. La Ciudad Letrada. Montevideo: Arca, 1998.

RAMÓN, Gabriel. Con la patria en las paredes. La regularización de la nomenclatura urbana de Lima (1861). Contracorriente. Revista de Historia, n. 1, p.85-99, nov. 1997.

SCHMIDT-WELLE, Friedhelm (coord.). La historia intelectual como historia literaria. (Estudios de lingüística y literatura, 61) México: D. F.: El Colegio de México, Centro de Estudios Lingüísticos y Literarios, Cátedra Guillermo y Alejandro de Humboldt, 2014.

SKINNER, Quentin. Meaning and Understanding in the History of Ideas. History and Theory, n. 1, p.3-53, 1969.

SUÁREZ DE LA TORRE, Laura Beatriz (coord.). Constructores de un cambio cultural. Impresores-editores y libreros en la ciudad de México. 1830-1855. México: Instituto de Investigaciones Dr. José María Luis Mora/Consejo Nacional de Ciencia y Tecnología, 2003.

SUÁREZ DE LA TORRE, Laura Beatriz (coord.); CASTRO, Miguel Ángel (ed.). Empresa y cultura en tinta y papel, 1800-1860. México: Instituto Mora, Universidad Nacional Autónoma de México, Instituto de Investigaciones Bibliográficas, 2001.

TORRE VILLAR, Ernesto de la. Breve historia del libro en México. México: UNAM, 1999.

TREJO, Evelia; MATUTE, Álvaro (eds.). Escribir la historia en el siglo XX, 30 lecturas. México: UNAM, IIH, 2005.

WHOL, Robert. The Generation of 1914. Cambridge, MA: Harvard University Press: 1979.

ZÁRATE TOSCANO, Verónica. La música conmemorativa en el México decimonónico. En Música de la Independencia a la Revolución. Artes de México, n. 97, p.34-43, p.74-75, abr. 2010.

ZÁRATE TOSCANO, Verónica. La sinfonía de la identidad mexicana en la música a fines del siglo XIX. In: SUÁREZ DE LA TORRE, Laura Beatriz (coord.). Los papeles para Euterpe. La música en la Ciudad de México desde la Historia Cultural, Siglo XIX. México, D. F.: Instituto Mora: 2014. p.230-289. 
ZÁRATE TOSCANO, Verónica. Nomenclatura y Nacionalismo. La materialización de la memoria en la ciudad de México en el siglo XIX. In: GIRON, Nicole (coord.). La construcción del discurso nacional en México, un anhelo persistente, (siglos XIX y XX). (Historia política) México: Instituto Mora, 2007. p.329-384.

ZERMEÑO, Guillermo. La cultura moderna de la historia. Una aproximación teórica. México: El Colegio de México, 2002. 